\title{
DEVELOPMENT OF HIGHER EDUCATION CURRICULUM IN SINGAPORE EDUCATION SYSTEM
}

\author{
Andria Pragholapati \\ Postgraduate School, Curriculum Development, Indonesian University of Education
}

\begin{abstract}
The curriculum is one component that has a strategic role in the national education system. The higher education curriculum is a set of plans and arrangements regarding the objectives, content, and teaching materials and ways used as guidelines to organize learning activities to achieve higher education goals. Different education systems in each country are important elements in the key to the success of education in a country. One country that competes with Indonesia is the Singapore Education system.
\end{abstract}

\section{INTRODUCTION}

The curriculum is one component that has a strategic role in the national education system. The higher education curriculum is a set of plans and arrangements regarding the objectives, content, and teaching materials as well as the ways used as guidelines to regulate learning activities to achieve higher education goals (DIKTI Law No.12, 2012). Based on the definition of education, it is stated that education is a conscious conscious effort. Educational planning will be included in the curriculum as a path or path in running the wheels of education in order to achieve educational goals.

The curriculum has two meanings. First as a number of subjects that must be studied by students. Second, special learning programs. In the curriculum, there is a set of subjects that must be taught at every level of education. Where every subject has its own curriculum. The curriculum of each subject is related to the competencies that must be achieved in each subject so that the hours of study are also arranged in it.

The curriculum contained in the education system in each country has its own style based on a country's national education goals. So as to understand the education system and curriculum of other countries against the domestic curriculum can also be obtained from comparative education studies or comparative education. Comparative Study of Education or Comparative Education is an effort to compare two different education systems both between regions and between countries, education comparison emphasizes more on the practical side, namely the activity of comparing two different education systems.

Different education systems in each country are important elements in the key to the success of education in a country. One country that competes with Indonesia is Singapore. 


\section{KAJIAN TEORI}

Sistem Pendidikan Singapura

Profil Negara Singapura (Singapore)

Singapura adalah sebuah negara maju yang terletak di Asia Tenggara. Negara pulau yang hanya memiliki luas wilayah $697 \mathrm{~km}^{2}$ ini memegang peranan penting dalam perdagangan dan keuangan internasional. Negara yang sebelumnya merupakan koloni Inggris ini pernah bergabung ke Federasi Malaysia pada tahun 1963 setelah memperoleh kemerdekaan dari Inggris. Namun dua tahun kemudian yaitu tahun 1965, Singapura berpisah dengan Federasi Malaysia dan resmi menjadi negara yang berdaulat. Tanggal 9 Agustus 1965 yaitu tanggal berpisahnya Singapura dengan Federasi Malaysia diperingati sebagai Hari Kemerdekaan Singapura.

Sebagai negara maju, Singapura memiliki pendapatan perkapita yang sangat tinggi yaitu sebesar USD. 87.100,- dengan Pendapatan Domestik Bruto nominal (PDB Nominal) sebesar USD. 487,9 miliar. Pendapatan Perkapita tersebut menjadikan Singapura sebagai salah satu negara terkaya di Dunia. Tulang punggung perekonomian Singapura adalah pengolahan barang impor dan ekspor terutama pada industri manufakturing seperti elektronik, pengolahan minyak bumi, bahan kimia, perkapalan, pengolahan karet dan pengolah makanan. Selain industri manufakturing, Industriindustri lain yang penting bagi perekonomian Singapura adalah perbaikan kapal, jasa keuangan dan perbankan, pariwisata serta perdagangan entrepot (pelabuhan perlintasan kapal). Pelabuhan Kargo Singapura yang melayani perdagangan entrepot ini merupakan salah satu pelabuhan kargo tersibuk di dunia. Pertumbuhan ekonomi Singapura pada tahun 2016 adalah sekitar $2 \%$.

Secara Astronomis, Singapura terletak di antara $1^{0} 11^{\prime} \mathrm{LU}-1^{0} 28^{\prime} \mathrm{LU}$ dan $103^{0} 38^{\prime} \mathrm{BT}-104^{0} 5^{\prime}$ BT. Singapura merupakan negara pulau yang tidak memiliki perbatasan darat dengan negara lainnya. Jika dilihat dari perbatasan lautnya, Singapura berbatasan dengan Malaysia di sebelah Utaranya yang dipisahkan oleh Selat Johor. Sedangakan di sebelah Selatannya berbatasan dengan Indonesia dengan Selat Singapura sebagai batas pemisahnya.

Sistem Pemerintahan yang dianut oleh Singapura adalah sistem pemerintahan Republik Parlementer yang kepala negaranya adalah seorang Presiden. Presiden Singapura dipilih langsung oleh rakyatnya setiap 6 tahun. Sedangkan kepala pemerintahannya adalah Perdana Menteri yang dipilih oleh setiap 5 tahun melalui pemilihan umum parlemen.

Singapura memiliki jumlah penduduk sebanyak 5.781.728 jiwa, mayoritas penduduknya adalah etnis Tionghoa yaitu sekitar $74,3 \%$ kemudian diikuti oleh etnis Melayu dan etnis India yang masing-masing berjumlah $13,4 \%$ dan $9,1 \%$ dari keseluruhan jumlah penduduk Singapura. Terdapat 4 bahasa yang ditetapkan sebagai bahasa resmi Singapura. Keempat bahasa tersebut diantaranya adalah bahasa Inggris, bahasa Mandarin, bahasa Melayu dan bahasa Tamil.

Di hubungan luar negeri, Singapura merupakan salah satu dari lima negara pendiri ASEAN pada tahun 1967. Lima Negara Pendiri ASEAN ini diantaranya adalah Indonesia, Malaysia, Filipina, 
Thailand dan Singapura. Singapura juga merupakan anggota APEC dan PBB serta lembagalembaganya lainnya yang dibawah PBB.

\section{Pendidikan di Singapura}

Dengan skor 0,768, Singapura tidak hanya memiliki salah satu sistem pendidikan berkualitas terbaik di ASEAN, tapi juga dunia. Saat ini negeri kepulauan tersebut menempati posisi sembilan dalam Indeks Pendidikan UNESCO. Tahun 2013 silam tercatat hanya 1,3\% murid sekolah yang gagal menuntaskan pendidikan.

Pendidikan pra-universitas (Junior Collage dan Central Institute)

Pendidikan pra-universitas mempersiapkan para siswa untuk pendidikan lanjutan di universitas. Untuk itu siswa harus mengikuti ujian Sertifikasi Umum Pendidikan Tingkat Lanjutan (GCE Tingkat A) pada akhir proses Pendidikan pra-universitas mereka. Setelah menyelesaikan ujian GCE Tingkat O, siswa dapat melanjutkan pendidikan pra-universitas mereka pada Junior College (JCs) selama2 tahun, atau Institut Terpusat (CI) selama 3 tahun. Pada akhir masa pendidikan prauniversitas, siswa harus mengambil ujian tingkat Singapura-Cambridge General Certificate of Education 'Advanced' (GCE A).

Jurusan Subyek yang Tersedia

Sains Matematika, Matematika lebih jauh, Fisika, Kimia, Biologi, Ekonomi, Komputer, Sastra Inggris, Geografi, Sejarah Seni Matematika, Sastra Inggris, Sejarah, Geografi, Ekonomi, Studi Teater dan Drama,Seni dan Desain, Musik Semua Jurusan Proyek Kerja, Bahasa Ibu, Pendidikan Umum di Cina, Perancis, Jerman, Jepang,Kewarganegaraan dan Pendidikan Jasmani Manajemen Bisnis dan Prinsip Akuntansi hanya ditawarkan dalam Institut Terpusat (IC) Program Pilihan Seni, Bahasa Perancis, Bahasa Jerman, Bahasa Jepang, Bahasa Melayu TingkatTinggi, Bahasa Cina Tingkat Tinggi, Musik

Institut Pendidikan Teknik

Institut Pendidikan Teknik (ITE) dibentuk sejak tahun 1992 untuk menggantikan Dewan Pelatihan Industri dan Kejuruan (VITB), menerima siswa berdasarkan hasil ujian GCE tingkat O atau GCE tingkat N. ITE biasanya menjadi pilihan terakhir siswa yang tidak masuk Junior Collage atau Politeknik. ITE menyediakan pelatihan 2 tahun dengan tiga tingkat kelulusan : (1). Sertifikat ITE Nasional (Nitec), (2). Higher National ITE Certificate (Nitec Tingkat Atas), dan (3). Sertifikat ITE Master Nasional (Master Nitec), dan juga Diploma Insinyur Teknologi Teknik Mesin (TED). Beberapa lulusan ITE juga melanjutkan pendidikan di politeknik dan universitas.

\section{Politeknik}

Politeknik didirikan untuk menawarkan kursus industri tingkat diploma pada siswa, membekali mereka dengan bermacam pelatihan profesional yangmencakup keterampilan, pengetahuan, dan pengalaman yang relevan dengandunia industri yang bergerak maju sehingga mampu mengintegrasikan diri dalamdunia kerja yang sesuai dengan minat dan bakat mereka. Siswa diterima berdasarkan nilai GCE Tingkat O, nilai GCE Tingkat A atau hasil Institut Pendidikan Teknik. Sebagian besar mahasiswa politeknik segera memasuki dunia kerja setelahkelulusan dan 
sedikit dari mereka yang melanjutkan pendidikan mereka ke suatuuniversitas.Saat ini di Singapura terdapat 5 politeknik (dengan urutan dari yangterlama ke terbaru), 1. Singapura Politeknik, 2. Ngee Ann Polytechnic, 3. Temasek Polytechnic, 4. Nanyang Polytechnic, 5. Politeknik Republik

Pendidikan Tinggi

Saat ini ada 4 universitas di Singapura. Pertama dua universitas, National University of Singapore dan Nanyang Technological University adalah universitas pemerintah, masing-masing memiliki sebuah pendaftaran dari sekitar 200.000 siswa. Universitas ketiga, Singapore Management University adalah universitas swasta yang didanai oleh pemerintah. Terakhir universitas, SIM University, adalah swasta. Siswa menerima gelar yang diakui secara internasional setelahmenyelesaikan kuliah mereka di universitas. Selain juga terdapat sepuluh lembaga pendidikan tinggi swasta lainnya yang memberikan gelar sarjana dan pascasarjana.Lembaga-lembaga pendidikan tinggi ini menjadi sarana bagi siswa untuk meningkatkan pendidikan dan pengalaman akademis mereka sehingga dapatmenghadapi persaingan di dunia kerja yang terus bergerak maju, membukakesempatan luas bagi mereka untuk berpartisipasi dalam peningkatan perekonomian Singapura.

\section{REFERENCES}

Ade, M.S., Tjutju, Pragholapati, A., 2016. GAMBARAN KUALITAS HIDUP PADA LANSIA DI BALAI PERLINDUNGAN SOSIAL TRESNA WERDHA CIPARAY BANDUNG TAHUN 2016.

http://ejurnal.stikesbhaktikencana.ac.id/file.php?file=preview_mahasiswa\&id=532\&cd=0b2173f f6ad6a6fb09c95f6d50001df6\&name=JURNAL\%20SAKINAH\%202016.pdf.

Andria Pragholapati, M.L., 2017. HUBUNGAN MASALAH KESEHATAN JIWA DENGAN STRATEGI KOPING SESEORANG YANG MENGALAMI PERCERAIAN DI KOTA BANDUNG, in: Seminar Nasional Dan Workshop Keperawatan "Penguatan Profesi Keperawatan Dalam Peningkatan Pelayanan Keperawatan" Continuum of Care Dari Ketergantungan Menuju Kemandirian Hidup Yang Berkualitas. ISBN: 978-602-14422-8-9.

Andria Pragholapati, R., 2018. DEVELOPMENT OF THE INDONESIAN NATIONAL QUALIFICATIONS FRAMEWORK FOR NURSING CURRICULUM, in: International Conference on Education and Regional Development 3rd (ICERD) 2018 "Curriculum for Generation of Discruptive and 4th Industry Revolution Era." p. 44.

Andria Pragholapati, R.M., 2017. HUBUNGAN BULLYING DENGAN KEMAMPUAN SOSIAL PADA REMAJA DI SMK MVP KOTA BANDUNG TAHUN 2017, in: Konferensi Nasional Keperawatan Kesehatan Jiwa XIV Di Kalimantan Selatan Tahun 2017.

Andria Pragholapati, T., 2018. HUBUNGAN PENGGUNAAN SMARTPHONE DENGAN KUALITAS TIDUR PADA REMAJA DI SMK X BANDUNG, in: Konferensi Nasional 
Keperawatan Kesehatan Jiwa XV Di Hotel Four Point By Sheraton Makassar Sulawesi Selatan. pp. 1-7.

Ardiana, F., Nurlianawati, L., Pragholapati, A., 2016. Gambaran Fungsi Kognitif Pada Lanjut Usia (Lansia) Di Panti Jompo Muhammadiyah dan Yayasan Pondok Lansia Tulus kasih.

Ariani, A., Pragholapati, A., Pratama, A.S., 2020. Information Communication Technology (ICT) In Midwifery Education: A Review of the Literature, in: The 3rd International Seminar on Global Health (ISGH) "Technology Transformation in Health Care for Better Life" Bandung, West Java, Indonesia. http://repository2.stikesayani.ac.id/index.php/isgh3/article/view/352, pp. 66-69.

Ismawati, Y., Pragholapati, A., 2020. KEJADIAN GASTRITIS DI DESA CINUNUK WILAYAH KERJA PUSKESMAS CINUNUK KABUPATEN BANDUNG.

Ismawati, Y., Sumbara, Pragholapati, A., 2018. HUBUNGAN POLA MAKAN DENGAN KEJADIAN GASTRITIS DI DESA CINUNUK WILAYAH KERJA PUSKESMAS CINUNUK KABUPATEN BANDUNG.

Pragholapati, A., 2020. Self-Efficacy Of Nurses During The Pandemic Covid-19.

Pragholapati, A., 2020. COVID-19 IMPACT ON STUDENTS. osf.io.

Pragholapati, A., 2020. RESILIENSI PADA KONDISI WABAH COVID-19.

Pragholapati, A., 2020. STRES KERJA PERAWAT YANG BEKERJA DI UNIT GAWAT DARURAT (UGD) RUMAH SAKIT AL ISLAM (RSAI) BANDUNG.

Pragholapati, A., 2020. MOTIVASI KERJA PERAWAT DI RUANG RAWAT INAP RSUD MAJALAYA KABUPATEN BANDUNG.

Pragholapati, A., 2020. MENTAL HEALTH IN PANDEMIC COVID-19.

Pragholapati, A., 2020. RESILIENSI PERAWAT YANG BEKERJA DI UNIT GAWAT DARURAT (UGD) RUMAH SAKIT AL ISLAM (RSAI) BANDUNG.

Pragholapati, A., 2020. NEW NORMAL “INDONESIA” AFTER COVID-19 PANDEMIC.

Pragholapati, A., 2019. THE EFFECT OF BRAIN GYM TO THE LEVEL OF DEPRESSION IN GERIATRIC AT BALAI PERLINDUNGAN SOSIAL TRESNA WERDHA CIPARAY BANDUNG. J. Sk. Keperawatan 5, 128-146.

Pragholapati, A., Munawaroh, F., 2020. RESILIENSI PADA LANSIA. J. Surya Muda 2, 1-8.

Pragholapati, A., Ulfitri, W., 2019. Gambaran Mekanisme Coping pada Mahasiswa Program Studi Sarjana Keperawatan Tingkat IV yang Sedang Menghadapi Tugas Akhir di Sekolah Tinggi Ilmu Kesehatan X Bandung. Humanit. J. Psikol. 3, 115-126.

Prasetyo M, D., Nurlianawati, L., Pragholapati, A., 2017. GAMBARAN TINGKAT KECEMASAN PADA PASIEN PRE OPERASI FIBROADENOMA MAMMAE DI RUANG 
$\begin{array}{llllllll}\text { GUNTUR RUMAH } & \text { SAKIT } & \text { TK } & \text { II } & \text { DUSTIRA } & \text { CIMAHI } & \text { TAHUN } & \end{array}$ http://ejurnal.stikesbhaktikencana.ac.id/mahasiswa.php?detail=mahasiswa\&id ....

Rahmawati, S.D., Mulyati, T., Pragholapati, A., 2015. HUBUNGAN BODY IMAGE DENGAN POLA DIET PADA REMAJA PUTRI DI SMAN 24 BANDUNG TAHUN 2015. http://ejurnal.stikesbhaktikencana.ac.id/file.php?file=preview_mahasiswa\&id ....

Rosmala, I., Jundiah, S., Pragholapati, A., 2017. TINGKAT KECEMASAN PADA KELUARGA PASIEN DI RUANG ICU RSUD MAJALAYA KABUPATEN BANDUNG TAHUN 2017. http://ejurnal.stikesbhaktikencana.ac.id/file.php?file=preview_mahasiswa\&id=517\&cd=0b2173f f6ad6a6fb09c95f6d50001df6\&name=Jurnal\%20Imas\%20Rosmala\%202017.pdf.

Septriani, D., Sari, Y.R., Pragholapati, A., 2019. The Relationship of Social Support With the Anxiety Level of Parents of Children with Thalassemia of Pre-School Age that Works in the Activities of Blood Transfusion in Hospital " $X$ " Bandung, in: The 2nd Bandung International Conference on Collaborative Health Research Research. Prama Grand Preanger Hotel Bandung, West Java, Indonesia 7th - 8th of October 2019. p. 12.

Virgona, A., Pragholapati, A., 2019. Enhancing Critical Thinking Skills in Nursing Higher Education in Preparation for the Industrial Revolution 4.0: Literature Review, in: The 3rd International Seminar on Global Health (ISGH) "Technology Transformation in Health Care for Better Life" Bandung, West Java, Indonesia.

Portal Rasmi Kementerian Pendidikan Malaysia. Diakses dari https://moe.gov.my/index.php/my/kurikulum

Yunardi. (2014). Sistem Pendidikan di Thailand. Diakses dari http://www.atdikbudbangkok.org/Sistem-Pendidikan-di-Thailand.pdf

http://unesdoc.unesco.org/images/0021/002152/215280E.pdf

http://unesdoc.unesco.org/images/0015/001524/152453eo.pdf

https://www.icnvoicetolead.com/wpcontent/uploads/2017/04/ICN_AVoiceToLead_guidancePack-9.pdf

Pragholapati, A. (2020). Depression in Someone Who Has Divorce.

Pragholapati, A. (2020). Anxiety in Someone Who Has Divorce.

Pragholapati, A. (2020). The Role of Nurses in Divorce.

Pragholapati, A. (2020). Marriage and Divorce.

Pragholapati, A. (2020). Mental Health Issues Someone Who Has Divorce. 
Pragholapati, A. (2020). Coping Strategies for Someone Divorced.

Pragholapati, A., \& Indonesia, P. RESILIENSI PADA KONDISI WABAH COVID-19.

Pragholapati, A. (2020). RESILIENSI PERAWAT YANG BEKERJA DI UNIT GAWAT DARURAT (UGD) RUMAH SAKIT AL ISLAM (RSAI) BANDUNG.

Pragholapati, A. (2020). NEW NORMAL "INDONESIA" AFTER COVID-19 PANDEMIC.

Pragholapati, A. (2020). STRES KERJA PERAWAT YANG BEKERJA DI UNIT GAWAT DARURAT (UGD) RUMAH SAKIT AL ISLAM (RSAI) BANDUNG.

Pragholapati, A. (2020). MOTIVASI KERJA PERAWAT DI RUANG RAWAT INAP RSUD MAJALAYA KABUPATEN BANDUNG.

Pragholapati, A. (2020). MENTAL HEALTH IN PANDEMIC COVID-19. Available at SSRN 3596311. 